\title{
BMJ Open WHO guidance for refugees in camps: systematic review
}

\author{
Harriet Blundell, ${ }^{1}$ Rachael Milligan, ${ }^{1}$ Susan L Norris, ${ }^{2}$ Paul Garner ${ }^{1}$
}

To cite: Blundell $\mathrm{H}$, Milligan $\mathrm{R}$, Norris SL, et al. WHO guidance for refugees in camps: systematic review. BMJ Open 2019;9:e027094. doi:10.1136/ bmjopen-2018-027094

- Prepublication history and additional material for this paper are available online. To view these files, please visit the journal online (http://dx.doi. org/10.1136/bmjopen-2018027094).

Received 10 December 2018 Revised 10 June 2019 Accepted 19 August 2019
Check for updates

(C) Author(s) (or their employer(s)) 2019. Re-use permitted under CC BY-NC. No commercial re-use. See rights and permissions. Published by BMJ.

${ }^{1}$ Department of Clinical Sciences, Liverpool School of Tropical Medicine, Liverpool, UK ${ }^{2}$ Health Metrics and Measurement, World Health Organization, Geneva, Switzerland

Correspondence to Professor Paul Garner; Paul.Garner@LSTMed.ac.uk

\section{ABSTRACT}

Objectives The circumstances of people living in refugee camps means that they have distinct medical care requirements. Our objective is to describe clinical guidance in published WHO guidelines that refer to people living in refugee camps; and how evidence and context are used and reported in making recommendations.

Design Systematic review and analysis of WHO guidelines approved by the organisation's quality oversight body and published between 2007 and 2018. We sought for key terms related to camps and humanitarian settings, and identified text that included guidance. We compared this to Mèdecins Sans Frontièrs (MSF) guidelines.

Results No WHO guideline published in the last 10 years focused exclusively on clinical guidance for healthcare in camp settings. Seven guidelines contained guidance about camps; three made recommendations for campsbut only two used formal evidence summaries. We did not find any structured consideration of the situation in camps used in the decision-making process. We examined seven WHO guidelines and six chapters within guidelines that concerned humanitarian settings: none of these documents contained recommendations based on formal evidence summaries for camp settings. One of the eight MSF guidelines was devoted to clinical care in refugees and the authors had clearly linked the health problems and recommendations to the setting, but this guideline is now $>20$ years old.

Conclusions There is an absence of up-to-date, evidence-based medical treatment guidelines from WHO and MSF that comprehensively address the clinical needs for people living in camps; and there is no common framework to help guideline groups formulate recommendations in these settings. WHO may wish to consider context of special populations more formally in the evidence to decision-making approach for clinical guidelines relevant to primary care.

\section{INTRODUCTION}

Worldwide, 8.7 million people are living in temporary communal settlements in 61 countries. ${ }^{1}$ In recent years, the influx of refugees from countries such as Syria affected by civil war or conflict into bordering countries and into Europe has garnered international attention on the ongoing crisis. There may be even more people living in temporary communal settlements given the ongoing crises in Syria and Myanmar, the sociopolitical
Strengths and limitations of this study

- This is the first systematic analysis of how well WHO guidelines cover the specific clinical health needs of people in refugee camps.

- This analysis also explores whether WHO applies an evidence to decision-making framework to use evidence of effects when drawing up recommendations for healthcare to meet the specific needs and conditions of people living in refugee camps.

- Some of the guidelines were prepared prior to the formal publication of evidence to decision-making procedures so some panels may not have considered the need for more formal procedures for adapting evidence to a refugee or humanitarian context.

stigmatisation of camps and the absence of good quality location data.

These temporary communal settlements include planned camps put in place by national governments or international agencies; self-settled camps developed by effected populations; transit camps used by people travelling through a country or region; and collective centres-where an existing building is repurposed. Refugees have international protection under the 1951 Refugee Convention and its 1967 Protocol. $^{2}$

Although 26.4 million people of concern are recorded as living in individual accommodation, 8.7 million still live in planned camps, self-settled camps, transit camps and collective centres. There are also a large number of people of concern whom location of accommodation is unknown (19.8 million) according to United Nations High Commissioner for Refugees (UNHCR). ${ }^{1}$

For simplicity, all temporary communal settlements will be referred to as 'camps' in this paper. While people living in camps have varying status according to the United Nations, they are labelled as 'people of concern' (table 1). The table outlines definitions used in the paper for people of concern, drawing on UNHCR and Amnesty International. $^{34}$

People living in camps face a range of health, social and environmental hazards 


\begin{tabular}{|c|c|}
\hline Term & Definition \\
\hline Refugees & $\begin{array}{l}\text { People who have fled their country because they are at serious risk of human rights violations and/ol } \\
\text { persecution. }\end{array}$ \\
\hline $\begin{array}{l}\text { Internally displaced } \\
\text { people }\end{array}$ & $\begin{array}{l}\text { People who have fled their home because they are at serious risk of human rights violations and/or } \\
\text { persecution but have not left their home country. They do not have international protection. }\end{array}$ \\
\hline Asylum seekers & People seeking international protection abroad, but who are not yet recognised as a refugee. \\
\hline Stateless people & $\begin{array}{l}\text { People who have been denied a nationality and therefore have difficulty accessing basic rights, } \\
\text { including for example education, healthcare, employment and freedom of movement. }\end{array}$ \\
\hline $\begin{array}{l}\text { People in refugee-like } \\
\text { situations }\end{array}$ & $\begin{array}{l}\text { This includes migrants who may have moved to find work or better living conditions or felt an } \\
\text { overriding need to leave their homes due to poverty or other serious situations. } \\
\text { This term may also include returnees, or people who have recently returned to their country of origin } \\
\text { after displacement. }\end{array}$ \\
\hline
\end{tabular}

that can impact their well-being. For example, poor water and sanitation, food insecurity, lack of essential medications, loss of primary caregivers and exposure to extreme temperatures. Overcrowding combined with poor vaccination coverage contributes to the risk of infectious disease outbreaks. ${ }^{5}$ Forced displacement, violence, rape and loss of family members all contribute to mental health problems. ${ }^{6}$ People are often vulnerable and poor, which contributes to the risk of sexual abuse and domestic violence. ${ }^{7}$ This results in people with a wide variety of healthcare requirements, in a setting where services may be foreign, difficult to access and poorly staffed.

The personal experience of two of the authors (HB, SN) was that national guidelines were often ill-fitting, volunteer providers from different countries felt inexperienced in managing these patients, and global guidelines-such as those issued by WHO-did not take the context into account. We found some Mèdecins Sans Frontièrs (MSF) guidelines that did take the context into account-for example, in highlighting the absolute priority of measles vaccination in the 1997 MSF guidelines. ${ }^{8}$

We (the authors) have all been involved to some degree in WHO guideline development for clinical topics, and in particular the more recent formal procedures of moving from evidence to decision-making through transparent, structured approaches. ${ }^{9}$ Our aim initially was to assemble a resource of relevant WHO guidelines that used Grading of Recommendations, Assessment, Development and Evaluations (GRADE) and was explicitly adapted to clinical care for managing people living in camp settings. We found almost no relevant material in the WHO in our initial comprehensive assessment.

We therefore decided to describe healthcare guidance that refers to people living in camp settings contained in published WHO guidelines; the nature of that guidance; and how evidence and context is used and reported in making recommendations. This modified aim was to help WHO prospectively consider the needs of these special groups in their guideline development across all relevant topic fields. As there was little clinical guidance for camp settings, we carried out a two-step process to describe what there was in camps, and also more broadly in guidance tailored to any humanitarian setting. To provide a gold-standard comparator, we compared the WHO guidelines with MSF guidance as their pioneering work in providing care to displaced populations is recognised, and their guidelines clearly showed they had considered factors relevant to context into account.

\section{METHODS}

Our inclusion criteria were all WHO guidelines approved by the Guidelines Review Committee (GRC), the internal quality assurance body established in 2007 to ensure that WHO guidelines are trustworthy and have optimal impact. $^{8} 9$ We included the most recent versions of approved guidelines, and only those published in English. We contacted the GRC to ensure we had a complete set of all guidelines. MSF guidelines are widely used and recognised as a benchmark in camp and humanitarian settings, so we drew on these as a comparator. MSF guidelines were identified through the MSF website ${ }^{10}$ and their online repository of guidelines. ${ }^{11}$

For both WHO and MSF guidelines, we sought guidance about people in camps by free-text searching for 1 of 15 key terms: 'emergency', 'conflict', 'disaster', 'humanitarian', 'war', 'asylum', 'displaced', 'forcibly', 'refugee', 'migrant', 'returnee', 'stateless', 'camps', 'settlement' and 'temporary'. We examined each occurrence of these key terms to establish if they were being used in reference to a camp setting, humanitarian setting, and if explicit guidance was being provided to the reader.

Guidelines containing only comments about affected populations or cross-references to other guidelines were excluded at this step. The guidance that explicitly addressed camp settings was then described. We sought recommendations that explicitly drew on formal evidence summaries; and we sought guidance statements where a course of action was proposed, but without reference to formal evidence summaries. We sought initially to divide other guidance statements into 'good practice' (recommendations without explicit consideration of the evidence, usually when the authors assume high net benefit supported by a large body of indirect evidence) 


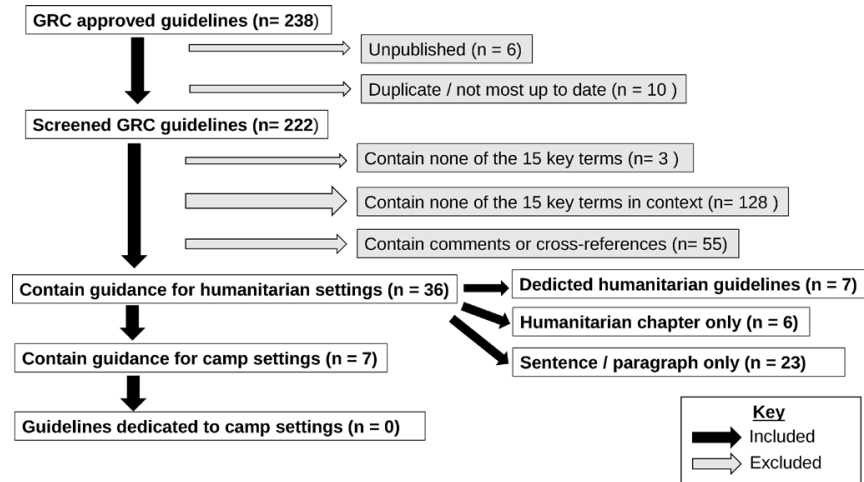

Figure 1 Adapted PRISMA flow diagram for screening of WHO GRC approved guidelines. GRC, Guidelines Review Committee; PRISMA, Preferred Reporting Itemsfor Systematic Reviews and Meta-Analyses.

statements based on ethics principles or human rights; or into guidance about implementation and delivery, but these categories were not possible to identify.

For each recommendation that explicitly drew on formal evidence summaries, we evaluated whether these recommendations were linked to evidence synthesised using the GRADE framework. GRADE is a transparent system used to develop and present summaries of evidence in order to make robust clinical practice recommendations, and is generally required for WHO guidelines. ${ }^{8}$

\section{Patient and public involvement}

The question for the evaluation arose out of practical experience providing medical care in camps $(\mathrm{SN})$ and whether the care, and the guidance of health professionals matched the needs of these vulnerable groups. Refugees, patients or the public were not involved in the design of this research.

\section{RESULTS}

The search results are displayed in figures 1 and 2 (screening of WHO and MSF guidelines), table 2 (WHO guidelines that refer to camp settings and propose a

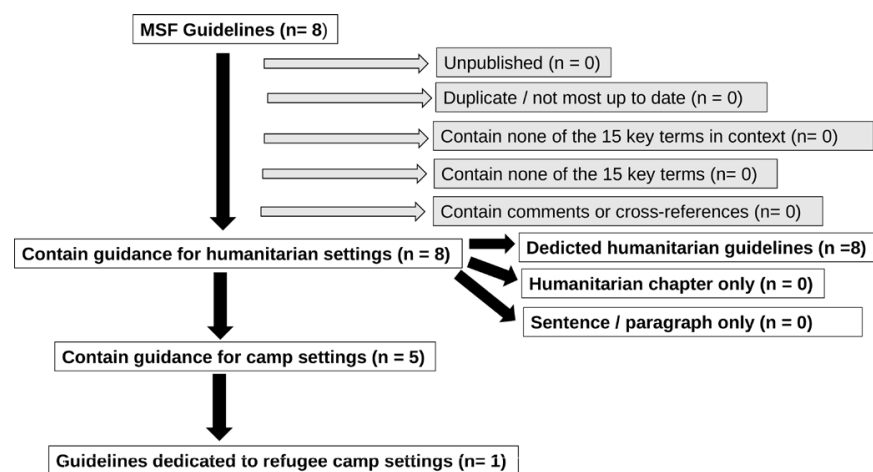

Figure 2 Adapted PRISMA flow diagram for screening of MSF guidelines. MSF, Mèdecins Sans Frontièrs; PRISMA,PreferredReporting Items for Systematic Reviews and Meta-Analyses. course of action) and table 3 (topics covered in WHO guidelines that refer to humanitarian settings).

\section{WHO guidance for camp settings}

Out of 222 GRC approved WHO guidelines, there were none dedicated exclusively to camp settings. Seven WHO guidelines on specific topics provided explicit guidance for the care of people living in camps (table 2).

Three of these seven guidelines included recommendations for camp settings, two guidelines on tuberculosis (TB) contained evidence-based recommendations (table 2). One TB guideline ${ }^{12}$ included evidence-based recommendations using the GRADE system to assess the evidence; a single study to support one recommendation; and another recommendation was transplanted from other WHO guidelines. The single evidence-based recommendation in the other $\mathrm{TB}$ guideline used a GRADE system which included a study carried out in a refugee camp to inform the acceptability of screening for the detection of active TB. ${ }^{13}$ One paediatric guideline contained a recommendation that was not linked to a formal appraisal of evidence. ${ }^{14}$

\section{MSF guidelines}

There were eight MSF guidelines published between 1997 and 2018 that met our inclusion criteria (online supplementary annex 1). One guideline was dedicated to healthcare professionals delivering care in refugee settings, including camps ${ }^{15}$ it is over 20 years old. This guideline was designed to be practical for use in the field, and throughout the manual made reference to the particular conditions, for example, in explaining the problems faced and in formulating the recommendations. For example, with measles vaccination, the authors make clear this is an absolute priority, irrespective of the presence of cases; that high coverage must be maintained, and cases immediately assessed; and any outbreak needs review of strategies.

Measles is one of the most severe health problems throughout the world, killing 1 in every 10 children affected in developing countries. Displacement, overcrowding and poor hygiene in the camps are all factors that encourage the emergence of very large-scale epidemics. In Tuareg refugee camps in Mauritania, a survey over a five month period in 1992 showed that $40 \%$ of childhood deaths were due to measles as a result of insufficient immunization. The mass vaccination of children from 6 months to 15 years old should always be an absolute priority during the first week, and can be conducted together with the distribution of vitamin $\mathrm{A}^{15}$

For MSF, in addition to the refugee health manual, ${ }^{15}$ we found four guidelines published between 2006 and 2018 which provide some guidance for people living in camp settings within the text. These concerned communicable diseases (management of a measles epidemic, with specific advice on vaccine regimens in the camp 
Table 2 WHO guidelines that refer to camp settings and propose a course of action

$\begin{array}{lll}\text { Guideline } & \text { Type of statement } & \text { Specific text }\end{array}$

Inter-agency field manual on reproductive Several guidance statements

health in humanitarian settings ${ }^{20}$

For example, 'Every maternal death that occurs within a refugee camp should be recorded'; or 'Provide context for all reported data. If known, and safe to do so, provide information on the camps/clinics/districts from where the cases are reported. Be specific, for example, 'reported cases from X number of health facilities".

Manual for healthcare of children in humanitarian emergencies ${ }^{21}$

One guidance statement

"Vulnerable groups of children should be located in a safe place in the camp' (a recommendation for the prevention of HIV infection after the acute phase of an emergency).

Systematic screening of active $\mathrm{TB}^{22} \quad$ Recommendations based on evidence summaries (uses GRADE)

'Migrants including refugees and immigrants from high burden settings are considered as part of community screening. Community screening can be done by systematically screening individuals in shelters, refugee camps and other specific locations'.

TB infection control in healthcare facilities, Recommendations based on evidence congregate settings and households ${ }^{23}$

'To decrease TB transmission in congregate settings, cough etiquette and respiratory hygiene, and early identification, followed by separation and proper treatment of infectious cases should be implemented' (Strong recommendation, low quality of evidence).

\begin{abstract}
Pocket book of hospital care for children ${ }^{26}$ One recommendation with no supporting
\end{abstract}
One recommendation taken from another WHO guideline published prior to the establishment of the GRC

One recommendation based on a single study

Numerous guidance statements evidence summary

Infant and young child feeding ${ }^{27} \quad$ Several guidance statements

'Directly observed therapy (DOT) while a patient is on treatment is also recommended' linked to The Stop TB Strategy: building on and enhancing DOTS to meet the TB-related millennium development goals. ${ }^{24}$

Recommendation to screen people for TB prior to entering a congregate setting, based on a study in a correctional facility in Singapore. ${ }^{25}$

For example, 'In any congregate settings, overcrowding should be avoided'.

'The extra measles dose is also recommended for groups at high risk of death from measles, such as infants in refugee camps, infants admitted to hospitals, HIV positive infants and infants affected by disasters and during outbreaks of measles'.

For example, 'Shelters for families should be provided in preference to communal shelters. Breastfeeding women need private areas (as culturally appropriate) at distribution or registration points, and rest areas in transit sites'.

Community based rehabilitation guidelines $^{28}$

Several other guidance statements
For example, 'Provide advice and assistance to humanitarian stakeholders to make temporary shelters accessible to people with disabilities'.

A "recommendation based on evidence summaries" is defined as a statement supported by a formal appraisal of the evidence Other "guidance statements" make recommendations with no link to evidence appraisal (statements about good practice, or in line with ethical principles and human rights, or notes on how to deliver care).

GRADE, Grading of Recommendations, Assessment, Development and Evaluation; TB, tuberculosis.

setting) ${ }^{16}$ nutrition (management of pellagra in a camp in the clinical guidelines manual ${ }^{17}$ and rapid health assessment for refugees and displaced populations ${ }^{18}$ and public health engineering in precarious situations, ${ }^{19}$ both of which made reference to public health assessments tailored to the camp setting in part of the manual (online supplmentary annex 1).

\section{WHO guidance for humanitarian settings}

We were surprised not to identify any specific guidelines from WHO related to camps. We therefore expanded our analysis to include humanitarian settings-the context in which camps most commonly arise. Of the 222 guidelines in this cohort, 13 included guidance applicable to humanitarian settings. Six of these guidelines were wholly 
Table 3 Topics covered in WHO guidelines that refer to humanitarian settings

\begin{tabular}{|c|c|}
\hline Topic & WHO guideline \\
\hline Communicable diseases & $\begin{array}{l}\text { Policy statement on HIV testing and counselling in health facilities for refugees, internally displaced } \\
\text { people and other persons of concern. } \\
\text { Treatment of Malaria (3rd Edition) (2015) * } \\
\text { Implementing the WHO STOP TB Strategy (2008) * }\end{array}$ \\
\hline $\begin{array}{l}\text { Sexual and reproductive } \\
\text { health }\end{array}$ & Inter-agency field manual on reproductive health in humanitarian settings (2010 revision) \\
\hline Child health & Manual for the health of children in humanitarian emergencies (2008) \\
\hline $\begin{array}{l}\text { Nutrition and nutrition } \\
\text { interaction with } \\
\text { communicable diseases }\end{array}$ & $\begin{array}{l}\text { Infant and young child feeding - model chapter for textbooks for medical students and allied health } \\
\text { professionals (2009)* } \\
\text { Baby friendly hospital initiative - revised, updated and expanded for integrated care }(2009)^{\star} \\
\text { Communicable diseases and severe food shortage, WHO technical note }(2010) \\
\text { Guidelines on HIV and infant feeding }(2016)^{\star}\end{array}$ \\
\hline
\end{tabular}

${ }^{*}$ Chapter on humanitarian settings in a general guideline.

concerned with the humanitarian setting, while the remaining seven included a specific chapter. The clinical areas covered by these thirteen guidelines are summarised in table 3. A further 23 WHO guidelines contained guidance in the form of a paragraph or sentence related to humanitarian situations. None of these guidelines or guideline chapters presented information as to how they were adapted for humanitarian settings. These are listed in online supplementary annex 1 .

\section{DISCUSSION}

The study includes guidelines that have been developed prior to the formal evidence to decision-making approaches developed as part of GRADE which were published in 2016. While transparent evidence to decision-making taking context into account has been happening for much longer than this, the formal publication of these procedures occurs after some of the guidelines we had reviewed. Even so, it is important to note how ad hoc and unsystematic are the approaches in the WHO guidelines to considering the needs and circumstances of vulnerable groups, including refugees and people living in camps.

While the topic for our analysis is refugees in camps, refugees and displaced people are sometimes more highly dispersed. We maintained the intended analysis on this particular vulnerable group for two reasons: first, there remain large camps worldwide and acute care for these groups are important; and second, their circumstances are more clearly defined, and allow clearer thinking related to context that providers need to take into account in evidence to decision-making guideline processes.
MSF provides a manual for primary care in refugee settings which carefully identifies priorities, recommendations and implementation notes that take into account the camp setting, but this document is 20 or more years old. In all the current WHO guidelines, camps are mentioned only in passing. Camps appeared to be an incidental afterthought during guideline writing, or the authors felt they should underline healthcare needs in refugee settings without providing explicit guidance. There is no attempt to explicitly identify priority clinical conditions in camps or to evaluate medical options in the light of the circumstances. The applicability of evidence in other settings needs to be explicitly considered, along with the feasibility and acceptability of various treatment options in the formulation of recommendations.

WHO guidelines and chapters related to humanitarian crises do not make specific recommendations for camp settings; nor does the topic coverage in humanitarian crises appear to be strategic. There are, however, more comprehensive efforts in reproductive and child health, and in TB and malaria.

Developing global evidence-based guidance for people living in camp settings is challenging, owing to the diversity of settings and populations. It cannot be assumed that systematic reviews from general populations can simply be directly applied to camp and humanitarian settings. However, what is needed is more thoughtful and tailored guidelines that encompass common considerations and features of the camp environment when addressing priority health conditions. For example, we propose that the considerations listed in table 4 are a starting point when formulating recommendations focused on individual care, the camp environment or health services delivery. 
Table 4 Factors to consider when planning a guideline for people living in camp settings to guide topics, evidence synthesis and the formulation of recommendations

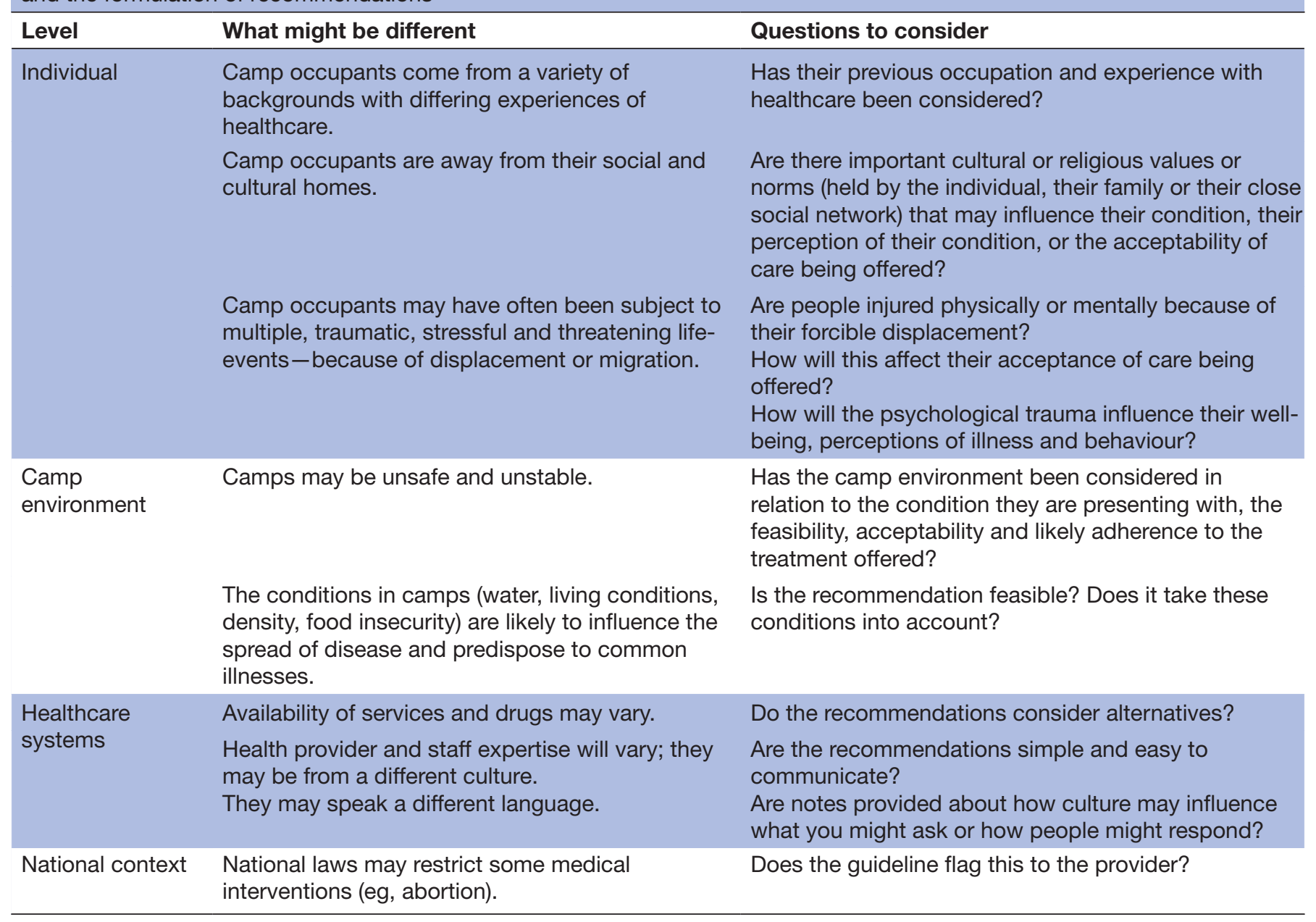

\section{CONCLUSION}

There is a need for current, evidence-based guidelines from WHO and MSF that provide explicit guidance tailored for managing common conditions in people living in camps. We propose that in their planning stage, all new WHO guidelines should consider whether recommendations to camps and humanitarian settings more broadly are relevant to the guideline topic, and if so, how the recommendations for more general populations might need to be adapted to these settings.

Second, guideline methodologists should urgently develop, implement and evaluate modified evidence-to-decision-making frameworks relevant to camps and humanitarian emergencies. Finally, WHO or another international agency should consider curating guideline collections across health topics relevant to the camp context, with appropriately adapted recommendations and guidance.

Contributors SN and PG originally conceived the project, RM and HJB developed the initial concept; all authors developed the question, HJB led the data extraction methods and analysis working with RM. All authors contributed to the analysis and writing of the paper.

Funding This publication is associated with the Research, Evidence and Development Initiative (READ-It) project (project number 300342-104), funded by UK AID.
Competing interests PG was a methods adviser to the WHO Malaria Treatment Guidelines Committee up to 2018; is a member of the GRADE Guidance Group, concerned with developing methods for transparent guideline development. SLN is the WHO Scientist in charge of the WHO Guidelines Review Committee; she is also an active member of the GRADE Working Group.

Patient consent for publication Not required.

Provenance and peer review Not commissioned; externally peer reviewed.

Data availability statement Data are available in a public, open access repository. All data relevant to the study are included in the article or uploaded as supplementary information.

Open access This is an open access article distributed in accordance with the Creative Commons Attribution Non Commercial (CC BY-NC 4.0) license, which permits others to distribute, remix, adapt, build upon this work non-commercially, and license their derivative works on different terms, provided the original work is properly cited, appropriate credit is given, any changes made indicated, and the use is non-commercial. See: http://creativecommons.org/licenses/by-nc/4.0/.

\section{REFERENCES}

1. UNHCR. 2014 statistical Yearbook table 17. population of concern to UNHCR by type of acommodation, end of 2014, 2014. Available: http://www.unhcr.org/statisticalyearbook/2014-annex-tables.zip

2. UNHCR. The 1951 convention relating to the status of refugees and its 1967 protocol. OnlineSeptember, 2011. Available: http://www. refworld.org/docid/4ec4a7f02.htm

3. UNHCR. Persons of concern to UNHCR, 2018. Available: http:// www.unhcr.org/ph/persons-concern-unhcr 
4. Amnesty International. Refugees, asylum seekers and migrants, 2018. Available: https://www.amnesty.org/en/what-we-do/refugeesasylum-seekers-and-migrants/

5. Hermans MPJ, Kooistra J, Cannegieter SC, et al. Healthcare and disease burden among refugees in long-stay refugee camps at Lesbos, Greece. Eur J Epidemiol 2017;32:851-4.

6. Keller A, Lhewa D, Rosenfeld B, et al. Traumatic experiences and psychological distress in an urban refugee population seeking treatment services. J Nerv Ment Dis 2006;194:188-94.

7. Al-Rousan T, Schwabkey Z, Jirmanus L, et al. Health needs and priorities of Syrian refugees in camps and urban settings in Jordan: perspectives of refugees and health care providers. East Mediterr Health J 2018;24:243-53.

8. WHO. WHO Handbook for Guideline development Geneva, 2014 Available: http://www.who.int/publications/guidelines/handbook 2nd_ed.pdf

9. Norris SL, Ford N. Improving the quality of WHO guidelines over the last decade: progress and challenges. Lancet Glob Health 2017;5:e855-6.

10. MSF. MSF medical guidelines, 2018. Available: https:// medicalguidelines.msf.org/viewport/MG/en/guidelines-16681097. html

11. MSF. MSF reference books, 2017. Available: http://refbooks.msf.org/ msf_docs/en/MSFdocMenu_en.htm

12. WHO. Who policy on TB infection control in health-care facilities. Congregate Settings and Households 2009.

13. WHO. Systematic screening for active tuberculosis - principles and recommendations, 2013

14. WHO. Pocket book hospital care for children. 2nd Edition, 2013.

15. MSF. Refugee health - an approach to emergency situations, 1997. Available: http://refbooks.msf.org/msf docs/en/refugee health/rh.pdf

16. MSF. Management of a measles epidemic, 2013. Available: http:// refbooks.msf.org/msf_docs/en/measles/measles_en.pdf

17. MSF. Refugees and displaced people, 2018. Available: https://www. msf.org.uk/issues/refugees-and-displaced-people
18. MSF, EpiCentre. Rapid health assessment of refugee or displaced populations, 2006. Available: http://refbooks.msf.org/msf_docs/en/ rapid_health/rapid_health_en.pdf

19. MSF. Public health engineering in precarious situations, 2010. Available: http://refbooks.msf.org/msf_docs/en/public_health/public health_en.pdf

20. Inter-Agency Working Group on Reproductive Health in Humanitarian Crises. Inter-agency field manual on reproductive health in humanitarian settings, 2010. Available: http://www.who.int/ reproductivehealth/publications/emergencies/field_manual/en/

21. WHO. Manual for the health care of children in humanitarian emergencies, 2008. Available: http://www.who.int/diseasecontrol_ emergencies/guidelines/child_health_care.pdf

22. WHO. Systematic screening for active tuberculosis - principles and recommendations, 2013. Available: http://www.who.int/tb/ tbscreening/en/

23. WHO. WHO policy on TB infection control in health-care facilities congregate settings and household, 2009. Available: http://apps. who.int/iris/bitstream/handle/10665/44148/9789241598323_eng. pdf? sequence $=1$

24. WHO. The stop TB strategy: building on and enhancing dots to meet the TB-related millenium development goals, 2006. Available: http:// www.who.int/tb/publications/2006/stop_tb_strategy.pdf

25. Chee CBE, Teleman MD, Boudville IC, et al. Contact screening and latent TB infection treatment in Singapore correctional facilities. Int $J$ Tuberc Lung Dis 2005;9:1248-52.

26. WHO. Pocket book of hospital care for children. 2nd Edition, 2013. http://apps.who.int/iris/bitstream/handle/10665/81170/ 9789241548373_eng.pdf?sequence=1

27. WHO. Infant and young child feeding: model chapter, 2009. Available: http://www.who.int/nutrition/publications/infantfeeding/ 9789241597494/en/

28. WHO. Community based rehabillitation guidelines, 2010. Available: http://www.who.int/disabilities/cbr/guidelines/en/ 